\title{
METODOLOGIA UTILIZADA NA ELABORAÇÃO DE CARTAS GEOTÉCNICAS DA APTIDÃO À URBANIZAÇÃ̃ FRENTE AOS DESASTRES NATURAIS NOS ESTADOS DE SANTA CATARINA E PARANÁ
}

\author{
Juan Antonio Altamirano Flores ${ }^{(a)}$, Joel Robert Georges Marcel Pellerin ${ }^{(b)}$, Janete Josina de \\ Abreu $^{(\mathrm{c})}$, Rafael Augusto dos Reis Higashi ${ }^{(\mathrm{d})}$

\begin{abstract}
(a) Prof. Dr. Departamento de Geociências. Universidade Federal de Santa Catarina, juan.flores@ufsc.br
(b) Prof. Dr Departamento de Geociências. Universidade Federal de Santa Catarina, pellerin@ @cfh.ufsc.br

(c) Profa. Dra. Departamento de Geociências. Universidade Federal de Santa Catarina, janete.abreu@ufsc.br

(d) Prof. Dr. Departamento de Engenharia Civil. Universidade Federal de Santa Catarina, rrhigashi@gmail.com
\end{abstract}

\section{Eixo: GEOGRAFIA FÍSICA E DESASTRES NATURAIS}

\begin{abstract}
Resumo
Esta metodologia atende aos objetivos do convênio entre o Ministério das Cidades e a Universidade Federal de Santa Catarina para elaboração de cartas geotécnicas de aptidão a urbanização frente aos desastres naturais. A metodologia inclui diversas etapas com destaque a duas delas, consideradas como principais: a cartografia geológica de detalhe de campo e os ensaios geotécnicos dos alteritos. Na carta geotécnica de aptidão são representadas três zonas: setores de baixa aptidão, média aptidão e alta aptidão à urbanização, considerando atributos do relevo, do substrato geológico e os resultados dos ensaios geotécnicos, que determinam a susceptibilidade aos diversos processos estudados. Desta forma são definidas recomendações para os planos diretores municipais, projetos de urbanização, parcelamento e uso do solo.
\end{abstract}

Palavras-chaves: cartografia geotécnica, aptidão à urbanização, deslizamentos, inundações, Santa Catarina.

\section{Introdução}

O convênio estabelecido entre a Universidade Federal de Santa Catarina, através do Departamento de Geociências, e a Secretaria Nacional de Desenvolvimento Urbano do Ministério das Cidades tem viabilizado a elaboração de Cartas Geotécnicas de Aptidão à Urbanização frente aos desastres naturais em 27 municípios do estado de Santa Catarina e 6 no estado do Paraná. Esta cooperação, que visa atender parte da Lei Federal 12.608/2012 (Brasil, 2012) que tem suas diretrizes voltadas à gestão e redução dos riscos de desastres naturais no país, em destaque para as ações preventivas. Esta prevê que os planos diretores municipais apontem áreas suscetíveis a processos do meio físico (Artigo $26^{\circ}$ ) e que a aprovação de novos projetos de parcelamento do solo urbano seja vinculada a adequação da ocupação urbana permanente do solo, de acordo com a suscetibilidade do terreno à ocorrência de processos físicos naturais ou induzidos, que possam representar ameaça à integridade física da população e às atividades socioeconômicas (Artigo $27^{\circ}$ ). Nos 27 municípios de Santa Catarina e 6 do Paraná são realizados a cartografia nos setores não urbanizados do perímetro urbano legal na escala 1:10.000. 
A elaboração das cartas geotécnicas de aptidão tem como base a realização de cartografia geológica, geomorfológica e hidrológica, apoiadas em trabalhos de campo e de laboratório, com a realização de análises sedimentológicas, de ensaios geotécnicos para caracterização geomecânica dos solos cartografados e de levantamento de perfis geofísicos.

A metodologia utilizada na elaboração destas cartas de aptidão permitiu a identificação de três classes de zoneamento, conforma segue:

- Classe de Baixa Aptidão à Urbanização, onde é recomendado não aprovar a ocupação permanente por razões físicas ou legais;

- Classe de Média Aptidão à Urbanização, onde à ocupação é permitida e condicionada a cuidados especiais a serem observados. Essa classe de aptidão apresenta diferentes subdivisões, em função dos processos ou problemas identificados;

- Classe de Alta Aptidão à Urbanização, onde a ocupação é permitida com poucas restrições, sem a necessidade de cuidados especiais, correspondendo aos setores favoráveis à ocupação permanente.

\section{Etapas da metodologia para elaboração da carta geotécnica de aptidão}

A metodologia utilizada na elaboração das cartas geotécnicas de aptidão à urbanização, entre os diversos itens abordados tem como base essencial a cartografia geológica e a realização dos ensaios geotécnicos dos solos cartografados (Figura 1). Esta metodologia comporta diversas etapas executadas simultaneamente ou sucessivamente (Flores et al, 2015), conforme relacionados a seguir:

1- Elaboração de base cartográfica. A partir dos dados do levantamento aerofotogramétrico da Secretaria do Estado do Desenvolvimento Sustentável de Santa Catarina (SDS) foram elaboradas imagens digitais ortorretificadas de alta resolução (pixels de $0.39 \mathrm{~m}$ ), que permitiram a geração de base cartográfica por interpolação de dados com alta precisão. Além dos dados planimétricos, os dados obtidos permitem a caracterização morfométrica das bacias. Os Modelos Digitais do Terreno (MDT) e derivados, permitiram a extração de uma base altimétrica tridimensional, com curvas de nível com equidistância de um metro, base dos mapas hipsométricos, de declividade e de fluxo hidrológico superficial pluvial e fluvial.

2- Inventário de registros de desastres. A coleta de registros de movimentos gravitacionais de massa e inundações foi obtida a partir de fontes de dados oficiais disponibilizados por órgãos de Defesa Civil de âmbito federal, estadual e municipal e não oficiais, como trabalhos acadêmicos, fontes midiáticas, entre outros. Este inventário possibilitou um primeiro panorama para a elaboração da carta de suscetibilidade (Brasil, 2007). 
XVII Simpósio Brasileiro de Geografia Fisica Aplicada

I Congresso Nacional de Geografia Física

\section{OS DESAFIOS DA GEOGRAFIA FÍSICA NA FRONTEIRA DO CONHECIMENTO \\ Instituto de Geociências - Unicamp \\ Campinas - SP \\ 28 de Junho à 02 de Julho de 2017}

3- Levantamento geológico e geomorfológico. A cartografia geológica efetuado no campo em escala detalhada é considerada como etapa fundamental para elaboração das cartas geotécnicas de aptidão. Na realização destas cartas é de suma importância a observação de dois tipos de dados: a litologia e as estruturas tectônicas (fig.1A e 1B).
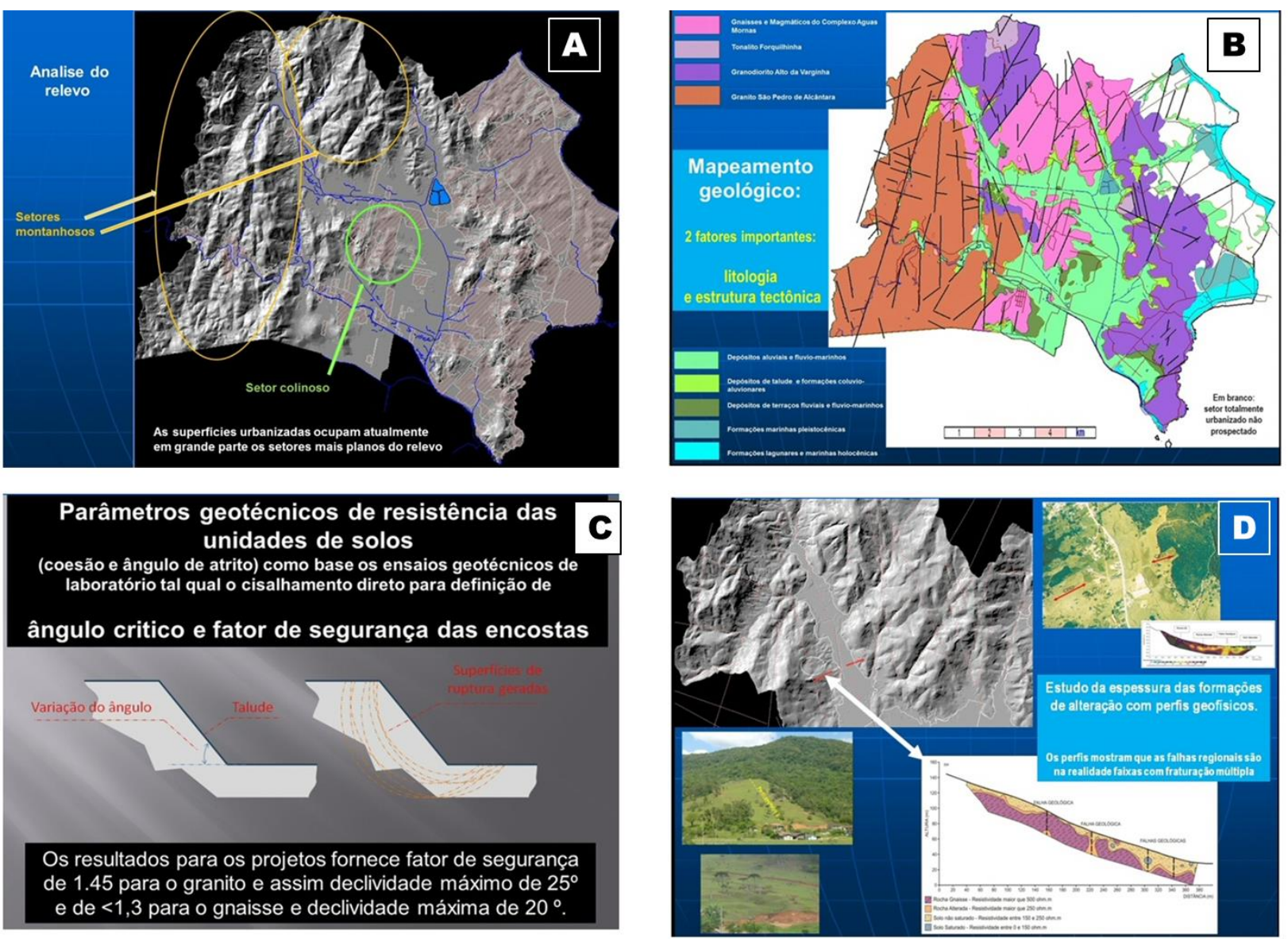

Figura 1 - Dados de base para a elaboração do mapa de suscetibilidade a deslizamentos: (A) analise do relevo; (B) carta geológico de detalhe; (C) resultados dos ensaios geotécnicos; (D) perfilagens geofísicas - Exemplos no município de São José /SC.

A ocorrência de estruturas tectônicas, como fraturas e falhas, aumenta a suscetibilidade das encostas aos movimentos gravitacionais de massas, ligados à heterogeneidade litológica, conforme foi constatado em diversos deslizamentos ocorridos no município de São José, na região metropolitana de Florianópolis, e evidenciada pelos dois perfis geofísicos realizados no município (fig. 1D). Em outro exemplo, no município de Ituporanga, situado na bacia do rio Itajaí do Sul, em contexto geológico da Bacia do Paraná, foi possível comprovar uma estreita correlação entre os locais com deslizamentos e os lineamentos estruturais da Zona de Cisalhamento Itajaí-Perimbó, que condiciona a instabilidade das rochas sedimentares, especialmente nas zonas cataclasadas, onde é mais intenso a saturação dos solos e das rochas, o intemperismo, os processos erosivos, e os movimentos de massa (Flores et al, 2016).

Uma complementação ao inventário dos deslizamentos é feita durante os levantamentos geológicos de campo, onde é dada atenção especial às áreas já afetadas por deslizamentos e seus entornos (identificação 
dos tipos de deslizamentos ocorridos e suas respectivas geometrias), com a caracterização dos processos atuantes no local.

4- Levantamento de perfis geofísicos. Estes levantamentos foram realizados por método geofísico de eletrorresistividade que complementaram os trabalhos de cartografia geológica de campo. Em São José, por exemplo, os resultados confirmaram a presença de espessos alteritos nas encostas do alto vale do rio Forquilhas e a forte fraturação dos litotipos que compõem o substrato rochoso e a identificação de diferentes falhas nos levantamentos realizados (fig.1 D).

5- Mapeamento geotécnico. Corresponde ao segundo elemento fundamental de elaboração das cartas de aptidão. Este procedimento está fundamentado nos ensaios geotécnicos de amostras de solos representativas das diversas formações geológicas de cada setor. São realizados ensaios de cisalhamento direto, com a definição de parâmetros geotécnicos de resistência dos solos (coesão e ângulo de atrito) para relacioná-los ao ângulo limiar de declividade das encostas quanto a suscetibilidade à deslizamentos (fig.1C). As amostras são coletadas nos diferentes horizontes pedogenéticos, com destaque para o horizonte $\mathrm{C}$, onde a proximidade com a rocha matriz inalterada e impermeável favorece as rupturas dos deslizamentos. A partir destes procedimentos é gerado um mapa de estimativa de unidades geotécnicas. Na elaboração desta carta é utilizado o modelo SHALSTAB (Shallow Slope Stability Model), baseado na combinação de modelos de estabilidade de encosta e modelos hidrológicos. Para a análise de estabilidade, o programa utiliza de um sistema de talude infinito, em que assume o estado de equilíbrio (steady-state), o fluxo paralelo à superfície e a lei de Darcy para estimar a distribuição espacial de poro pressões (Morrissey et al., 2001).

6- Cartografia de áreas susceptíveis aos deslizamentos. A carta de suscetibilidade aos deslizamentos elaborada por geoprocessamento está fundamentada no cruzamento das informações obtidas nos levantamentos geológicos, geomorfológicos e geofísicos e nos resultados das analises geotécnicas para cada variedade de solo (substrato rochoso, formações superficiais de alteração e sedimentos de acumulação das planícies sedimentares quaternárias). Na sequência é efetuada uma calibragem dos resultados obtidos com base no inventário de eventos (quando existem dados), com a identificação de cicatrizes no campo e os resultados da aplicação do modelo de estabilidade de encostas. O ajuste final dos perímetros das zonas ou unidades da carta de suscetibilidade na escala de detalhe é feito por fotointerpretação pelas equipes de geologia e geomorfologia, a partir do conhecimento adquirido no campo.

7- Mapeamento das áreas susceptíveis a inundação. As cartas de susceptibilidade à inundação são elaboradas através de uma combinação de dados de séries históricas de cota e vazão, classificação de MDT com HAND e também o uso "soft data" como informações coletadas por meio de registros oficiais disponíveis, entrevistas, visitas de campo e a experiência da equipe. A Figura 2 apresenta uma visão geral da metodologia utilizada. Nos municípios estudados por falta frequente ou inconsistência de dados 
XVII Simpósio Brasileiro

de Geografia Fisica Aplicada

I Congresso Nacional

de Geografia Física

\section{OS DESAFIOS DA GEOGRAFIA FÍSICA NA FRONTEIRA DO CONHECIMENTO \\ Instituto de Geociências - Unicamp \\ Campinas - SP \\ 28 de Junho à 02 de Julho de 2017}

hidrológicos, a estimação das áreas propensas à inundação é feita por meio de atributos topográficos da paisagem que surge como uma alternativa. Estes pontos servem para a validação do mapeamento pelo HAND. Também é verificado se há uma concordância espacial entre a planície de inundação e as áreas propensas à inundação, estando o mapeamento coerente com os processos geomorfológicos que ocorrem nas áreas próximas ao canal.

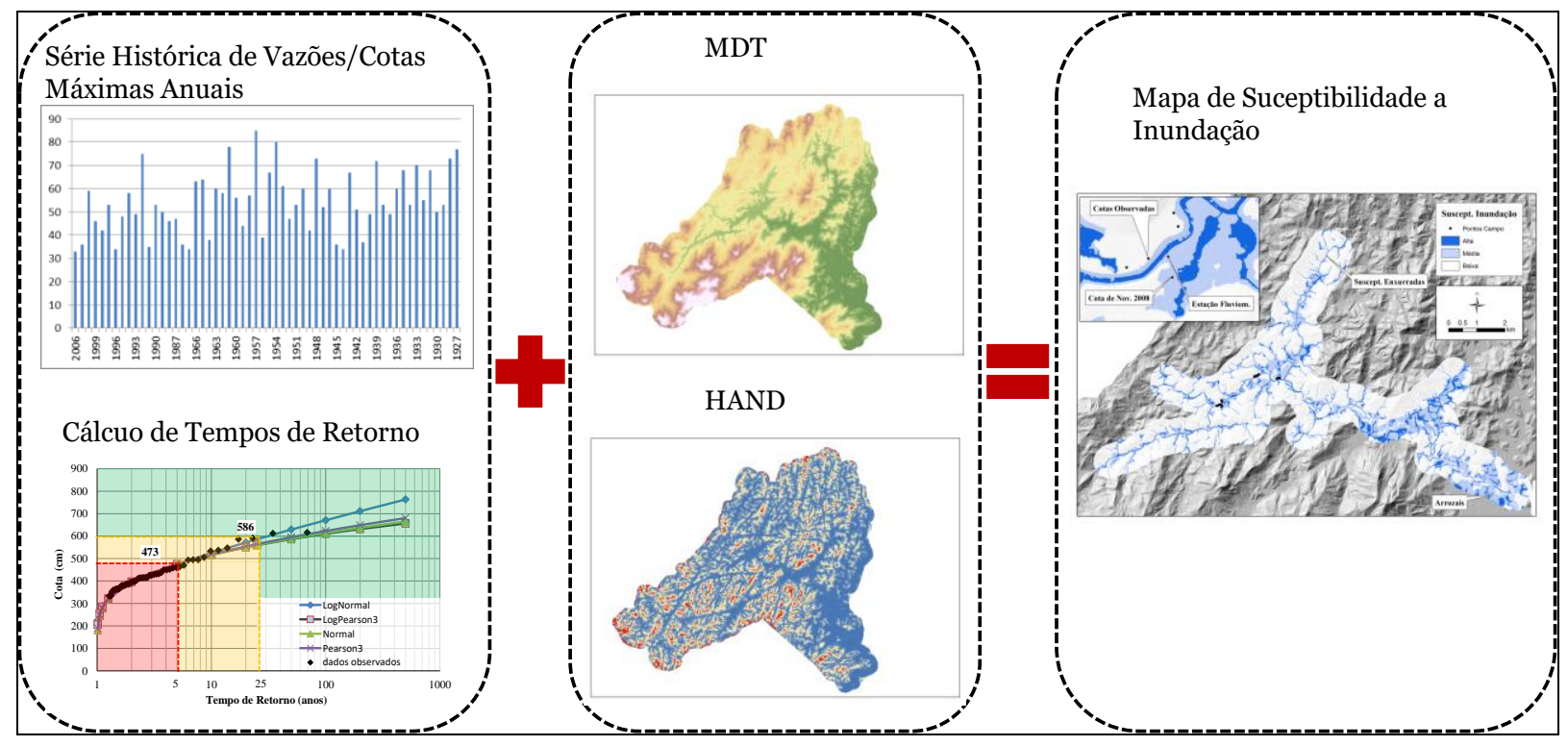

Figura 2 - Esquema metodológico para a cartografia das áreas de susceptíveis às inundações

8- Elaboração da carta geotécnica de aptidão à urbanização. A elaboração da carta de aptidão à urbanização resulta do geoprocessamento na escala de 1:10.000, e corresponde a uma síntese das cartas de suscetibilidade referentes à probabilidade de ocorrência de deslizamentos nas encostas e de inundações nas planícies dos municípios alvos do projeto, com base as características morfométricas, geológicas, geomorfológicas, geotécnicas, hidrológicas definidas anteriormente. A validação final resulta da reinterpretação dos dados e dos polígonos considerados como incorretos. Essa reinterpretação tem como base os dados levantados no campo pela equipe de geologia e geomorfologia

São assim estabelecidas zonas homogêneas em relação aos processos físicos e à aptidão urbana na área de estudo como indicado na legenda de cada carta (Fig. 4). Os dados sobre as Áreas de Preservação Permanente (APP) urbanas, oriundos de documentos legais dos municípios e do governo federal integraram os resultados dessa carta, porém são objetos apresentados separadamente. A legenda apresenta descrição dos processos físicos que podem ocorrer nas zonas de aptidão e as diretrizes específicas quanto a adequação para ocupação urbana das áreas mapeadas, fornecendo subsídios gerais para a legislação municipal, e o estabelecimento de políticas preventivas de proteção civil, com a indicação de áreas que precisam de detalhamento para avaliação geotécnica voltada à aptidão urbana, restrições quanto ao parcelamento do solo e instalação de loteamentos, a necessidade de obras de infraestrutura viária, 
saneamento e drenagem, e riscos potenciais a desastres naturais, conforme preconizado por Diniz et al.(2012).

A título de exemplo, a figura 3 apresenta a carta e a figura 4 a legenda da carta de Aptidão à Urbanização Frente aos Desastres Naturais para o município de São José, a qual está classificada em 3 zonas:

- baixa aptidão à urbanização (em vermelho): são zonas ou unidades territoriais com alta probabilidade de ocorrência dos processos analisados e que são consideradas inadequadas para a ocupação urbana permanente;

- média aptidão à urbanização (em amarelo): são zonas de média probabilidade de ocorrência dos processos considerados e que se traduzem por setores de ocupação permanente condicionada à implantação de cuidados especiais. Essa classe é subdividida em três, representadas por nuanças de amarelo, indicando os setores relacionados à suscetibilidade à deslizamentos, os setores relacionados à suscetibilidade a inundações e apresentando problemas geotécnicos e os setores de planícies não inundáveis apresentando solos compressíveis.

- alta aptidão à urbanização (em verde): as zonas de baixa probabilidade de ocorrência dos processos considerados, definidas como adequadas à ocupação urbana permanente. 


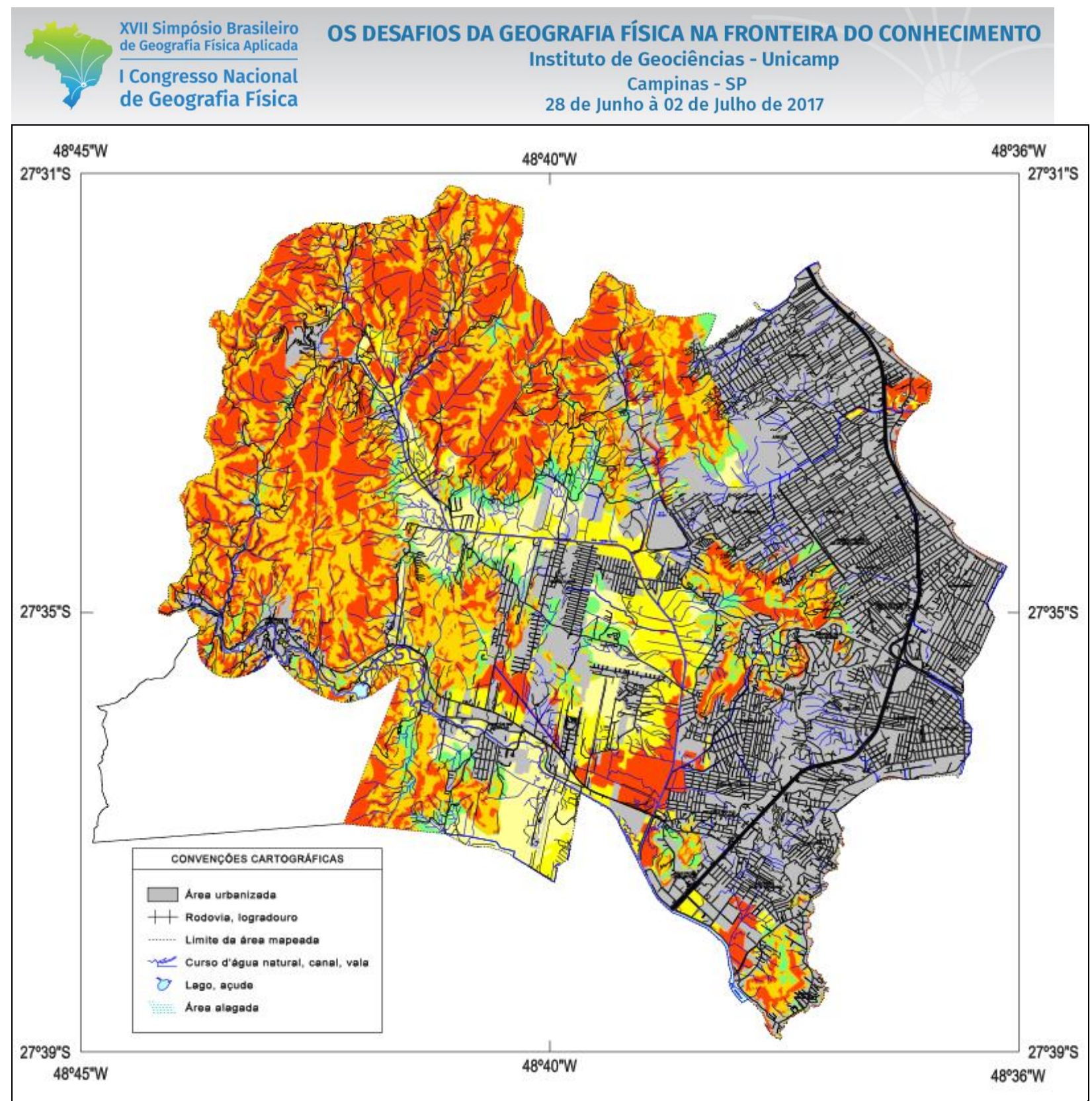

Figura 3 - Carta geotécnica de aptidão à urbanização das áreas suscetíveis à expansão urbana no município de São José (UFSC/Ministério das Cidades, 2016). 
XVII Simpósio Brasileiro de Geografia Fisica Aplicada

I Congresso Nacional de Geografia Física
OS DESAFIOS DA GEOGRAFIA FÍSICA NA FRONTEIRA DO CONHECIMENTO

Instituto de Geociências - Unicamp

Campinas - SP

28 de Junho à 02 de Julho de 2017

\begin{tabular}{|c|c|c|c|}
\hline \multicolumn{4}{|c|}{ L E G E N D A } \\
\hline CLASSE & $\begin{array}{l}\text { CARACTERIZACAO } \\
\text { DAS UNIDADES }\end{array}$ & PROCESSOS GEODINAMICOS & $\begin{array}{l}\text { DIRETRIZES PARA PROJETOS DE URBANIZACAOA, DE } \\
\text { PARCELAMENTO DO SOLO E DE EDIFICAÇOES }(*) \text { (**) }\end{array}$ \\
\hline $\begin{array}{l}\text { BAIXA APTIDAO } \\
\text { A URBANIZACGAO }\end{array}$ & 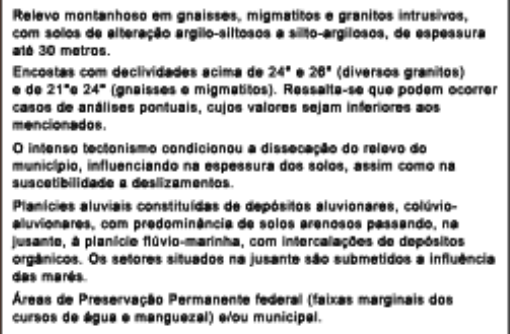 & 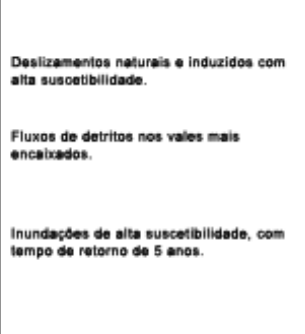 & 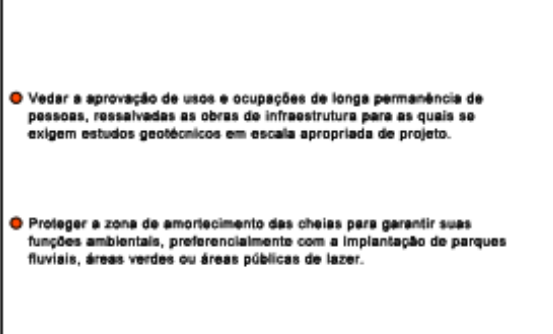 \\
\hline \multirow{4}{*}{$\begin{array}{l}\text { MEDDLA APTIDAO } \\
\text { A URBANIZACABO }\end{array}$} & 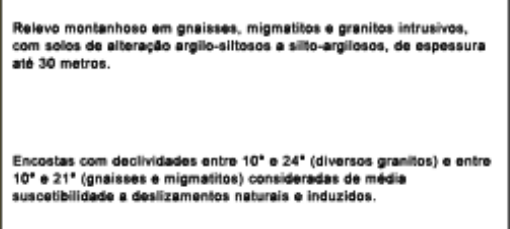 & 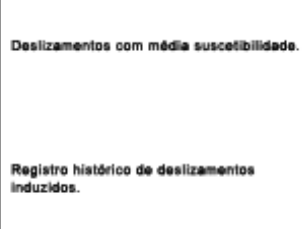 & 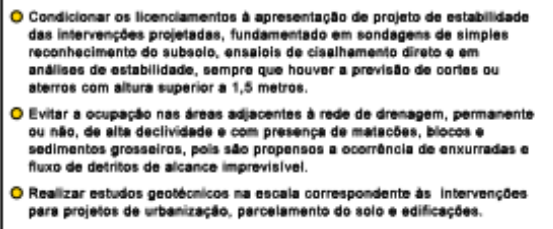 \\
\hline & 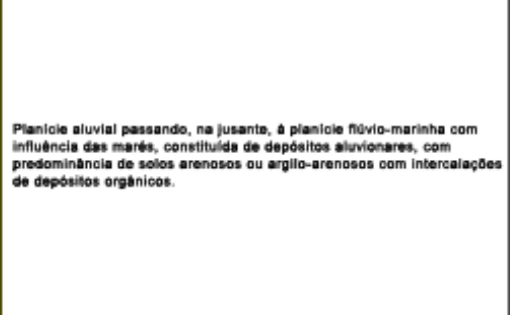 & 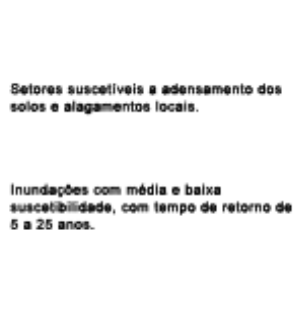 & 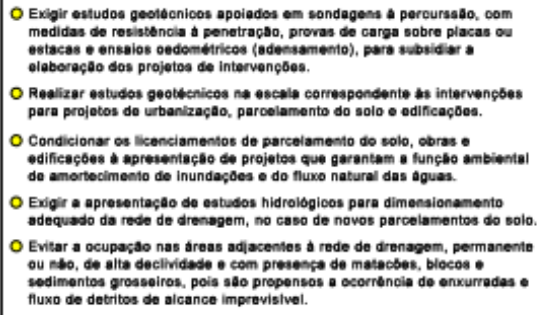 \\
\hline & 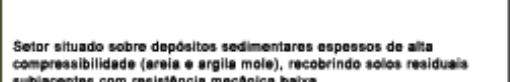 & 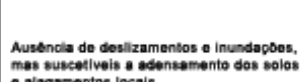 & 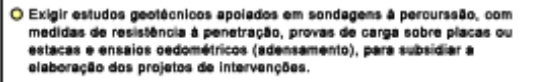 \\
\hline & 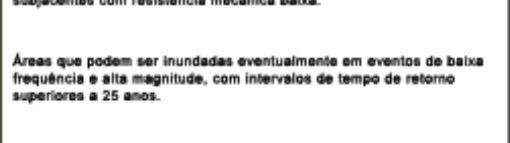 & $\begin{array}{l}\text { Plenicio com inumdapao am tempo do } \\
\text { remorno maior que } 25 \text { anos. }\end{array}$ & 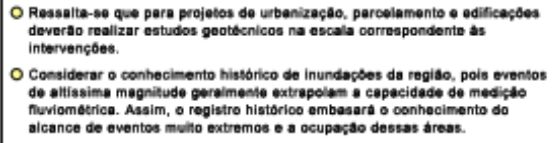 \\
\hline $\begin{array}{l}\text { ALTA APTIDAO } \\
\text { A URBANIZACGAO }\end{array}$ & $\begin{array}{l}\text { Seltores collinosos com encostas de declividade inferier a } 10^{*} \text {. } \\
\text { Praniciess aluviais. }\end{array}$ & Austinclas de dosilzamentos a inundapbes & 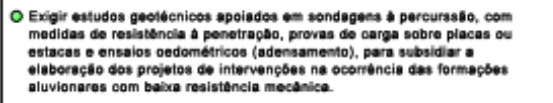 \\
\hline
\end{tabular}

(*) A Carte de Aptidao a Urbanizaçao fol realizada na escela 1:10.000, portanto, identifica as caracteristicas do meio fisico correspondentes a esta escala.

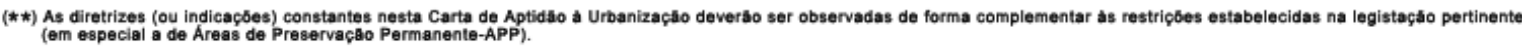

Figura 4 - Legenda da carta de aptidão á urbanização em São José

\section{9- Implantação de banco de dados georreferenciados e disponibilização dos mapas na WEB.}

A implantação do banco de dados georreferenciados foi desenvolvida com a utilização de um Sistema de Informação Geográfica (SIG) em ambiente Desktop, sendo algumas camadas inseridas em banco de dados geográfico e disponibilizadas em ambiente WEB. Este sistema compreende um conjunto de funções que possibilita automatizar o processo e disponibilizar aos profissionais maior capacidade de análise de dados georreferenciados. Realiza a interação entre dados descritivos (alfanuméricos) e dados espaciais (geográficos), e apresenta as seguintes características que podem ser aplicadas aos dados: armazenamento, recuperação, edição, análise e visualização de dados. O aplicativo de acesso à internet foi concebido com plataforma tecnológica livre, e hospedado no Datacenter da Superintendência de Tecnologia de Informação e Comunicação (SETIC) da Universidade Federal de Santa Catarina. 


\section{Bibliografia}

BRASIL. LEI No 12.608, DE 10 DE ABRIL DE 2012. Institui a Política Nacional de Proteção e Defesa Civil PNPDEC

BRASIL. Ministério das Cidades / Instituto de Pesquisas Tecnológicas - IPT. Mapeamento de Riscos em Encostas e Margem de Rios / CARVALHO, C. S.; MACEDO E. S. E OGURA A.T., organizadores - Brasília: Ministério das Cidades; Instituto de Pesquisas Tecnológicas - IPT, 2007. 176p.

DINIZ, N. C.; FREITAS DE, C.G.L.; NETTO, A. L. C.; MORETTI, R.; ZUQUIM, L.; SOUZA DE, N. M.; MACEDO DE, E.S.; ALHEIROS, M. 2012. Cartografia geotécnica. 37p.

FLORES, J.A.A.; PELLERIN, J.R.G.M.; NASCIMENTO, M.S.; PARIZOTO, D.G.V.; NOVOLETTO, V. Movimentos de massa em setores com complexidade geológica no perímetro urbano de Ituporanga, Santa Catarina. In. III CONGRESSO DA SOCIEDADE DE ANALISE DE RISCO LATINO AMERICANA. Anais..., ABGE/IPT, São Paulo, 2016

FLORES, J.A.A.; PELLERIN, J.R.G.M.; TOMAZOLLI, E.R.; ABREU, J.J.; HIGASHI, R.A.R; SANCHEZ, G.M. Cartas geotécnicas de aptidão à urbanização como instrumento de gestão de riscos e prevenção de desastres naturais: exemplo do município de São José. In $15^{\circ}$ CONGRESSO BRSILEIRO DE GEOLOGIA DE ENGENHARIA e AMBIENTAL, Bento Gonçalves/RS, out. 2015. Anais, nº. 385 CD Rom

MORRISSEY, M. M.; WIECZOREK, G. F.; MORGAN, B. A. A comparative analysis of hazard models for predicting debris flows in Madison County, Virginia. Open-File Report 01-0067, Report USGS, 2001,16p.

UFSC/MINISTERIO DAS CIDADES. Elaboração de cartas de aptidão à urbanização frente aos desastres naturais no município de São José, estado de Santa Catarina. Relatório final. UFSC, Florianópolis, 2016. (Relatório inédito).

\section{Agradecimentos:}

Os autores agradecem o Ministério das Cidades, através da Secretaria Nacional de Desenvolvimento Urbano, pelo o apoio financeiro para a pesquisa desenvolvida. Os agradecimentos se estendem a todos os membros das equipes ligados aos projetos dos departamentos de Geociências e de Engenharia Civil da Universidade Federal de Santa Catarina. 